\title{
Aneuploidy: a common and early evidence- based biomarker for carcinogens and reproductive toxicants
}

\author{
Daniele Mandrioli ${ }^{1}$, Fiorella Belpoggi ${ }^{1}$, Ellen K. Silbergeld ${ }^{2}$ and Melissa J. Perry ${ }^{3^{*}}$
}

\begin{abstract}
Aneuploidy, defined as structural and numerical aberrations of chromosomes, continues to draw attention as an informative effect biomarker for carcinogens and male reproductive toxicants. It has been well documented that aneuploidy is a hallmark of cancer. Aneuploidies in oocytes and spermatozoa contribute to infertility, pregnancy loss and a number of congenital abnormalities, and sperm aneuploidy is associated with testicular cancer. It is striking that several carcinogens induce aneuploidy in somatic cells, and also adversely affect the chromosome compliment of germ cells. In this paper we review 1) the contributions of aneuploidy to cancer, infertility, and developmental abnormalities; 2) techniques for assessing aneuploidy in precancerous and malignant lesions and in sperm; and 3) the utility of aneuploidy as a biomarker for integrated chemical assessments of carcinogenicity, and reproductive and developmental toxicity.
\end{abstract}

Keywords: Aneuploidy, Carcinogens, Reproductive toxicants, Endocrine disruptors, Chromosomes, Early diagnose, Bioassays, Risk assessment, mFISH, Laser scanning microscopy

\section{Background}

Biomarker of effect is defined as a measurable biochemical, physiologic or other alteration in an organism that is associated with an established or possible health impairment or disease [1]. Effect biomarkers have a central role for toxicological evaluations including in vitro studies in tissue samples, in vivo studies in animal models, and for early disease detection and monitoring of health status in humans $[2,3]$. Biomarkers of effect are widely explored in medicine [4], environmental epidemiology [5] and public health [6]. Together with the benefits for health and safety, using effect biomarkers may result in lower costs to the public, industry and governments favoring cost-effective approaches for disease prevention [7]. They can contribute to early detection and prediction of adverse effects, supporting prioritization and screening programs for substances of concern [8]. Their utility has resulted in an increasing demand for new and

\footnotetext{
* Correspondence: mperry@gwu.edu

${ }^{3}$ Department of Environmental and Occupational Health, Milken Institute School of Public Health, The George Washington University, 950 New Hampshire Ave. NW, 4th Floor, Washington, DC 20052, USA Full list of author information is available at the end of the article
}

informative biomarkers of effect. Aneuploidy, because its mechanisms are well known and its adverse effects are well established, is being increasingly used as an informative effect biomarker $[9,10]$. Aneuploidy is a hallmark of cancer and causes developmental abnormalities in all species where the condition has been examined [11, 12]. Aneuploidy is defined as "one or more whole chromosomes (numerical chromosomal aneuploidy) absent from or in addition to the euploid complement, or having one or more chromosome segments (segmental or structural aneuploidy) absent from or in addition to the euploid complement" [13]. The euploid complement, or the normal content of chromosomes for a cell, always exists as an exact multiple of the haploid number of chromosomes: germinal cells are haploid (1 copy of each chromosome, 23 chromosomes total), somatic cells are generally diploid (2 copies of each chromosome, 46 chromosomes total) and in some rare cases can be poliploid (more than 2 copies of each chromosome, for example muscle, macrophages). Therefore any gain or loss of chromosomal material by the euploid complement creates an-euploidy (in Greek euploidy literally means "normal form" -of the nucleus-, while an-euploidy 
means "abnormal form"). The role of aneuploidy in cancer and reproductive biology has been investigated since the last century, but only relatively recently have technical advances translated early findings from basic science to experimental, pathological and epidemiological settings. Following the early pioneering works by David Hansemann [14], it was the talented couple Theodore Boveri and Marcella O'Grady [15, 16] that in 1904 first provided systematic and detailed evidence of the role of aneuploidy in fertilization, development and cancer [1720]. They were already aware that chemical and occupational exposures could induce cancer, another pioneering view for the time, "the connection between cancer and certain chemical irritants is even clearer than it is between cancer and the physical agents I have mentioned. I need only refer to the cancers of paraffin workers." [21]. Other historical steps that elucidated the role of aneuploidy in cancer, reproductive, and developmental toxicity include: 1929, Barbara McIntock discovers the disruptive role of aneuploidy in maize development [22]; 1956, Julian Huxley introduces the concept of cancer as a new biological species with a high degree of genetic heterogeneity [23]; 1959, Jerome Lejeun discovers that an extra copy of Chromosome 21 causes Down Syndrome [24]; 1961, Theodore Hauschka documents that the euploid content in human and rodent tissues is strongly conserved and observes that leukemia cells are consistently aneuploid [25]; 1971, Andrě Pavlovich Dyban and Vladislav Sergeevitch Baranov show through Robertsonian translocation the reproductive and developmental effects of all the possible trisomies in mice [26]; and 1986, Mitsuo Oshimura and J. Carl Barrett elucidate the mechanisms of chemical induced aneuploidy in mammalian cells [27].

The mechanisms that link aneuploidy to adverse outcomes are well determined: aneuploid germinal cells encounter difficulty in normal fertilization and development and aneuploid tumor cells never express a normal phenotype. Down Syndrome is the best example of how a single extra copy of one of the smallest chromosomes (containing normal genes) may disrupt organs and cellular phenotypes. Down Syndrome patients with complete trisomy 21 present more severe symptoms and a more disrupted phenotype than incomplete trisomy 21 [2830]. In humans, copy number changes of autosomes (non-sex chromosomes containing normal genes) are generally not compatible with normal development or survival. In fact, all of the autosome copy number changes, with the exception of trisomy 21 (Down Syndrome), trisomy 18 (Edwards Syndrome) and trisomy 13 (Patau Syndrome), are not compatible with life after birth. Most babies born with trisomy 18 or 13 present several congenital abnormalities and die by age 1 [31, 32]. Recent mechanistic experiments on budding yeast have shown how aneuploidy directly affects gene expression at both the transcriptome and proteome levels and can generate significant phenotypic variation in a "dose dependent" fashion (the higher the degree of aneuploidy the higher the disruption of the phenotype) [33].

Yet, the presence of aneuploidy at the cellular level does not necessarily imply a disrupted phenotype at the organ level. High frequencies of aneuploidy have been reported in experimental conditions in the liver of knock-out mice after tyrosinemia-induced hepatic injury [34] and have been observed routinely through fluorescence in situ hybridization (FISH) in brain tissues of rodents and human [35], where mature aneuploid neurons were found to be functionally active and integrated into brain circuitry. This finding originally fueled speculation that aneuploidy might provide a selective advantage in these organs, but recent results obtained with single cell sequencing demonstrate that aneuploidy occurs much less frequently in the liver and brain than previously reported and is no more prevalent in these tissues than in skin [36]. In contrast, aneuploidy frequencies are significantly increased in organs affected by chronic degenerative diseases such as Alzheimer's disease, ataxia telangiectasia and liver cirrhosis [37, 38].

Because aneuploidy is well characterized and has multiple impacts on organismic health and development, it is an excellent biomarker for characterizing the reproductive toxicant and carcinogenic properties of chemicals. In the following sections we will review 1) the role of aneuploidy in cancer and reproductive toxicity; 2) the overlap among chemical classes between sperm genotoxicants, sperm aneuploidogens (substances inducing an altered number of whole chromosomes) and chemical carcinogens; 3) the different techniques available to assess aneuploidy in precancerous and malignant lesions and sperm; and 4) the experimental and epidemiological possibilities for integrating aneuploidy measurement into integrated chemical assessments.

\section{Aneuploidy in cancer and precancerous lesions}

Aneuploidy, which includes both numerical and structural chromosomal abnormalities, is a hallmark of cancer [11]. It is a common characteristic of cancer and precancerous lesions, regardless of whether the causative agents are genotoxic, which directly damage the DNA, or non genotoxic carcinogens that may indirectly induce aneuploidy via different mechanisms, for example favoring higher replication rates in a tissue (as in the case of carcinogens with hormonal activity) and increasing the risk of errors during replication (in fact at each replication there is an intrinsic risk in human cells of developing de novo aneuploidy in 1:1000-1:10000 cells) [39-43]. By unbalancing the expression of thousands of genes [44] and proteins [45], aneuploidy disrupts the normal cell 
phenotype [46] and automatically destabilizes the karyotype, altering replication mechanisms [47] and catalyzing random aneuploidy events in single mitotic steps [48]. Cells from the same tumor are known to be clonal and in fact they share the majority of the karyotype (including clonal markers and chromosomal rearrangements), but every single cancer cell presents de novo numerical and/ or structural chromosome rearrangements that are unique in each respective cell [49]. A recent analysis of 36,859 karyograms of 37 cancer types available in the Mitelman Database, the largest database of karyotypes of cancerous lesions from all sites maintained as part of the Cancer Genome Anatomy Project of the US National Cancer Institute (http://cgap.nci.nih.gov/Chromosomes/Mitelman), revealed that all the cancers were aneuploid; there was not a single case with a normal chromosome number $(n=46)$ that did not carry at least one structural or numerical aberration [50]. Indeed, karyotypic analysis of thousands of cancers has revealed the existence of karyotypic patterns, with aneuploidies that are recurrently found in several different cancer types, and others that are specific to individual tumors and tissues/organs of origin [51], but most aberrations appear to be non-specific and random [52], presenting individual, variant karyotypes, with characteristics each time resembling a new species $[49,53,54]$.

A fundamental distinction between cancer and precancerous cells is clonality: cancerous cells are clonal and aneuploid, which means all the cells from the primary and secondary lesions (metastasis) share the same ancestor and common markers $[55,56]$. Clonality is routinely used as strict criteria for the pathological diagnosis of cancer, particularly, for the diagnosis of leukemia and lymphoma, and it can be assessed with different techniques (IHC, GSH, FISH, PCR) [55, 57]. In contrast, precancerous cells in dysplastic lesions are consistently aneuploid but not clonal. This may be better explained by investigating the relation between aneuploidy and field carcinogenesis. Field carcinogenesis (or cancerization) predicts that cancer occurs more often over dysplastic precancerous lesions induced by carcinogens [58], a concept originally proposed by Slaughter in 1953 for oral cancer [59] that now applies to every epithelial site. This explains the preventive efficacy of early diagnosis and treatment of dysplastic local lesions arising in specific "fields", such as PAP-test (cervix cancer) [60], dysplastic polyps (colon cancer) [61], Barrett esophagus [62], leukoplakia (oral cancer) [63], and dysplastic nevi (melanoma) [64]. Virtually all dysplastic lesions present higher rates of aneuploid cells and their degree of aneuploidy often correlates with the likelihood of malignant progression in breast [65], colon [66], lung [67, 68], prostate [69], melanoma [70] oral [71], esophagus [72], cervix cancer [73] and leukemia [74].
Sperm aneuploidy can also be considered a preneoplastic lesion (e.g., men with Down and Klinefelter syndromes present higher rates of testicular cancer) as shown by Skakkebaek et al. [75]. Different authors have proposed tetraploidy as the first telltale step of the characteristic aneuploidy cascade of carcinogenesis [76-78]. Cancers have been shown to arise in non-clonal aneuploid dysplastic lesions induced by carcinogens in hamsters, mice, and rats exposed to carcinogens. When a clonal expansion occurs in dysplastic lesions, it is more appropriate to use the term carcinoma in situ, because clonality is an unique characteristic of cancer (carcinoma) cells $[79,80]$.

\section{Carcinogens cause aneuploidy}

Whereas in biology aneuploidy often refers to any chromosomal imbalance (any karyotype different from diploid for somatic cells or different from haploid in the case of germinal cells), many efforts have been attempted in toxicology to differentiate clastogens (substances inducing disruption or breakages of chromosomes, leading to sections of the chromosome being deleted, added, or rearranged), from aneuploidogens [81]. Both clastogens and aneuploidogens can lead to the formation of micronuclei, a small extra-nucleus containing a whole chromosome or a fragment of a chromosome [82]. Several techniques have been developed for distinguishing clastogens from aneuploidogens in micronuclei tests, for example through the presence of a centromere/kinetokore for whole chromosomes, which are absent in chromosome fragments [83]. The distinction between the two categories is interesting for mechanistic purposes, yet they do not preclude similar biological consequences. Both clastogens and aneuploidogens are more likely to be carcinogens [84, 85], many carcinogens are both clastogens and aneuploidogens (for example X-rays and benzene) [86, 87], and both aneuploidogens and clastogens are able to foster further chromosomal instability (both partial and whole chromosome loss and gain) [88, 89]. Overall mechanisms and the continuum of the effects seem directly proportional to the disruption of the chromosomes. The inclusive definition of aneuploidy provided by Dyer in 1970 seems most consistent with its biological effects, "one or more whole chromosomes (numerical chromosomal aneuploidy) absent from or in addition to the euploid complement, or having one or more chromosome segments (segmental or structural aneuploidy) absent from or in addition to the euploid complement." [13]. In fact, Oshimura and Barret, adopting Dyer's definition, further specified that "an aneuploidogen may or may not be a clastogen" and anticipated that "aneuploidy in the form of a partial or complete chromosome duplication represents one form of gene amplification" [27]. 


\section{Aneuploidy in sperm and reproductive toxicity}

Aneuploidy involving at least a single chromosome causes developmental abnormalities in all species where this condition has been examined [12]. An abnormal chromosome complement is thought to contribute to more than $50 \%$ of early losses [90]. Many new gene mutations seen in offspring [91-93] and several abnormalities in the numbers of the sex chromosomes [94] come from the father's sperm. Sperm aneuploidy is associated with infertility, miscarriages, and congenital abnormalities [95-97]. The most common aneuploidy in humans at birth involves an abnormal number of $\mathrm{X}$ or $\mathrm{Y}$ chromosomes, [98]. Children with sex chromosomal abnormalities, characterized in Klinefelter and Turner syndromes, can have reproductive disorders, behavioral difficulties, and/or reduced intellectual capabilities compared to their siblings [99, 100]. While US specific data are not available, European data from consecutive birth studies report the incidence of Klinefelter syndrome is increasing. A significant increase in the incidence of XXY trisomies in newborns between 1967 and 1988 has been reported [101], but no increases in the incidence of XXX or XYY trisomies. XXY trisomies frequently arise from nondisjunction of the XY (paternal) bivalent during meiosis I, and no observed increase in XXX trisomy (predominately maternally-derived) was observed, suggesting that there may be underlying environmental causes affecting non-disjunction during spermatogenesis. Data from the European Surveillance and Congenital Abnormalities [100] registry show significant regional differences in the prevalence of sex chromosome trisomies reported between 2000 and 2005; prevalence was lowest in Poland (0.19 per 10,000 births) and highest in Switzerland (5.36 per 10,000 births) [100]. These differences (up to 25 fold) might also be explained in part by the variation across European registries in the availability of prenatal screening (ultrasound and antenatal screening for Down's syndrome) as well as organizational and cultural factors [100].

Elevated rates of aneuploidy in sperm are correlated with higher frequencies of chromosomal abnormalities in preimplantation embryos [102, 103], lower fertilization and implantation rates [104], and higher miscarriage rates [105]. Increased disomy is associated with inferior semen parameters in multivariate adjusted models [106]. Aneuploidy occurs when meiosis is disrupted during gametogenesis. It is not known how genotoxicants interfere with the meiotic phase, but infertile men often have an impaired chromosome synapsis and an increased frequency of chromosomes that are missing a recombination site $[99,107]$. These errors make the cells susceptible to meiotic arrest and production of aneuploid gametes. Altered recombination impacts nondisjunction; nonrecombinant chromosomes are susceptible to nondisjunction due to reduced connections among homologous chromosome pairs [108]. Chemicals known to disrupt hormone signaling have been shown to affect mammalian recombination and germ cell aneuploidy [109], while other genotoxicants induce structural and numerical chromosomal aberrations that are not repaired by male or female DNA repair machinery during fertilization [110]. Changes in the endocrinologic environment of the testis affect the rate of meiotic segregation errors [111], and p, p'-DDE for example has been shown to impact calcium ion channels (CatSper) to affect $\mathrm{Ca} 2+$ increases which impact sperm capacitation, chemotaxis, hyperactivation, and acrosomal exocytosis [112]. Men exposed to genotoxic compounds have been found to have significantly higher frequencies of chromosomally abnormal sperm [113-115].

\section{Sperm aneuploidogens and carcinogens}

Carcinogens can be developmental and reproductive toxicants, but these effects may or may not follow similar pathways. How many carcinogens are capable of producing sperm aneuploidy and how many sperm aneuploidogens are also carcinogens? A complete answer is elusive to date, mainly because of the lack of sperm aneuploidy testing in experimental models and epidemiological cancer cohorts, but some initial evidence has emerged. A recent review of the reproductive health of men with occupational exposures [116] listed seven substances known to affect sperm genetic integrity: phthalates [117], styrene [118], organophosphates [119], carbaryl [120], fenvalerate [121], lead [122, 123], and benzene [124]. Six of these seven are known or suspected carcinogens according to the Report on Carcinogens of the US National Toxicology Program [125] or are listed by the State of California (http://oehha.ca.gov/prop65.html) as chemicals known to cause cancer. For one chemical (fenvalerate), adequate carcinogenicity data are not available. Chemicals that can induce sperm aneuploidy appear more likely to be carcinogenic. On the other hand, carcinogens should also be screened as potential sperm aneuploidogens, although it should be expected that only some of the aneuploidogens that are carcinogenic would also pass the blood-testis barrier. Additionally, germinal reproductive check points may prevent, at least in part, chromosomal damage. This is suggested by the finding that rates of aneuploid lymphocytes induced by benzene are significantly higher than aneuploidy rates in sperm [126]. Sperm aneuploidogens are often not only aneugenic to sperm, but also to other organs $[43,126-128]$. 


\section{Techniques available to assess aneuploidy in precancerous and malignant lesions and sperm}

Aneuploidy, as an effect biomarker, is not a substitute for other fundamental indicators in cancer cells, such as genes and markers of proliferation (Ki-67), receptors that identify the tissue of origin of the lesion (IHC), or proteomic and genomic (and epigenomic) profiling of cancer cells. The main value of aneuploidy as an effect biomarker is that is a measurable characteristic of virtually any biological and pathological tissue: it can differentially diagnose pre-cancerous and cancerous lesions. In terms of its utility for sperm assessment, aneuploidy is informative well beyond the standard sperm quality indicators such as concentration, motility and morphology. Owing to techniques such as Laser Scanning Microscopy (Figs. 1 and 2), aneuploidy can be evaluated on the same slide, at a single cell level of resolution, together with other techniques and biomarkers such as IHC and Ki-67 for an optimal evidence based evaluation of malignancy, clonality, tissue of origin and replication rate of the lesion [129-131]. Progress in semiautomatic sperm scoring has advanced precision in determining sperm aneuploidy rates while saving on time and operator burden $[132,133]$ and is making human biomarker assessment more feasible for both cancer biology and molecular epidemiology laboratories [134].

\section{Future developments}

Future advancements that will increase sensitivity in aneuploidy detection [135] include: improved interphase

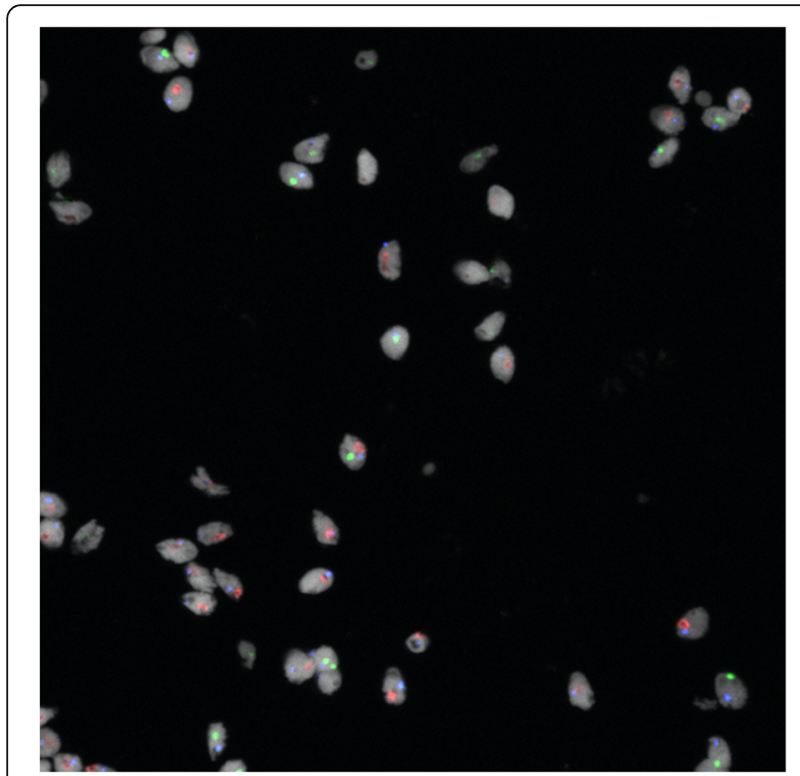

Fig. 1 Sperm Fluorescence in situ hybridization results for chromosomes 18, $X$ and $Y$. Full position image. Cells are displayed using a white for ToPro. Composite image of channels acquired for each of the four signals: SpectrumAqua (18), SpectrumGreen $(X)$, SpectrumOrange $(Y)$ and the nuclear stain

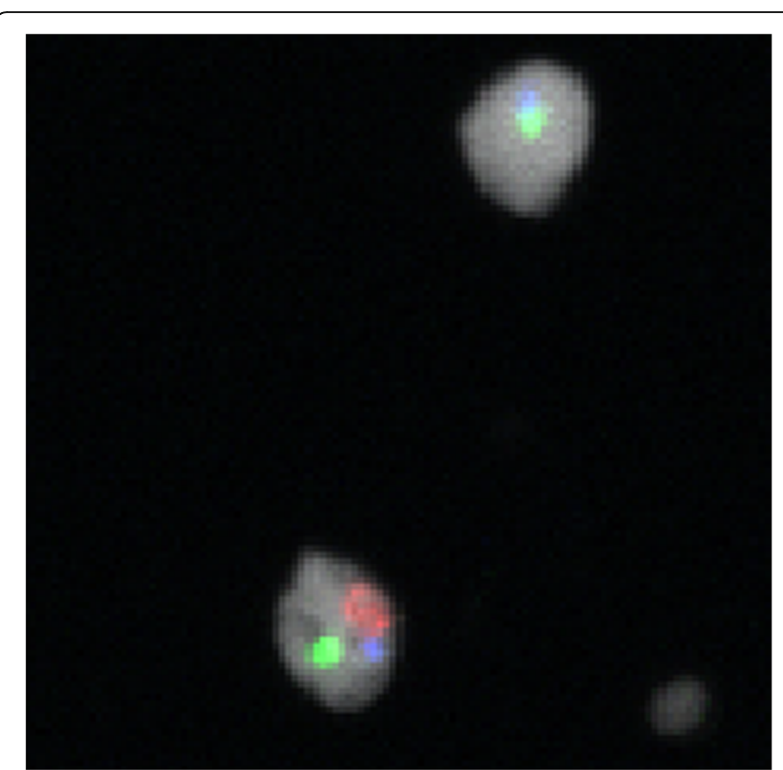

Fig. 2 Sperm Fluorescence in situ hybridization results for chromosomes 18, $X$ and $Y$. Snip image of the cells in white (cropped). Composite image of channels acquired for each of the four signals: SpectrumAqua (18), SpectrumGreen $(X)$, SpectrumOrange $(Y)$ and the nuclear stain

chromosome staining, with higher numbers of probes and aberrations tested on the same cell $[136,137]$ and the use of Quantum Dots that present higher fluorescence efficiency, lower photobleaching and vastly better photostability compared to organic fluorophores [138-140]. Another possible advancement will consist of the use of the specimens fixed in alcohol rather than formaldehyde [141]. Alcohol preserves DNA [142], RNA [143] and proteins [144] better than formaldehyde with comparable, if not superior, performance for molecular analysis, cytology and microscopy [145-148] and could dramatically lower the exposure of the operators to a known human carcinogen [149, 150].

Causes of oocyte aneuploidy are unknown, but it is the most common cause of pregnancy loss and birth defects [94]. Ovarian impacts are sometimes evaluated in toxicology studies, albeit less frequently than primary organs such as liver, lung, and brain. Oocyte aneuploidy might also be an interesting biomarker for chemical carcinogenicity or reproductive toxicity [151, 152]. Oocyte aneuploidy screening is likely also to advance in vitro fertilization techniques. In the controlled setting of the assisted reproduction clinic, aneuploidy in the embryo is the most frequently observed cause of failure to achieve a pregnancy. In this context, opportunities for more fully assessing oocyte aneuploidy are promising because women may be willing to donate remainder oocytes for epidemiologic and mechanistic studies [153-155]. 


\section{Conclusions}

Aneuploidy is an excellent candidate as an evidencebased biomarker for reproductive toxicants and carcinogens. This condition is a cellular hallmark of all cancerous and precancerous lesions across a spectrum of cell types, and in sperm specifically, it is associated with infertility, miscarriages, and congenital abnormalities. Hence, sperm aneuploidy is of particular interest because this condition is associated with both increased risk of cancer and reproductive toxicity. Assessment of sperm aneuploidy induced by exposure to chemicals in both experimental models and epidemiological studies has proven effective and predictive of the risk to humans: of seven substances known to affect sperm genetic integrity [116], six are known or suspected carcinogens [125]. In light of these findings and considering that with the advent of automated chromosome counters and Laser Scanning Microscopy, sperm aneuploidy assessment has become much faster and reliable, it should be included to extend the evaluation of sperm aneuploidy in chemical hazard and risk assessment. Assessment of aneuploidy in sperm germinal cells should be integrated with current aneuploidy and chromosome imbalance assessments currently in place for somatic cells (such as comet and micronuclei assessments of peripheral lymphocytes) [156]. Assessments in both somatic and germ cells are needed to ensure that a comprehensive evaluation of carcinogenicity and reproductive toxicity is completed and one assessment cannot be substituted for the other, as they each provide independent information on chemical health impacts $[157,158]$.

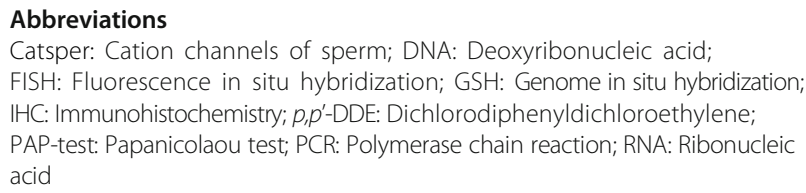

\section{Acknowledgements}

We authors would like to thank: the staff of the Cesare Maltoni Cancer Research Center, Ramazzini Institute; Linda Nguyen, George Washington University; Peter Duesberg and Amanda McCormack, UC Berkeley; Giovanni Pierini, University of Bologna; Francesco Ceci and Paolo Castellucci, Department of Nuclear Medicine, S.Orsola-Malpighi Hospital, Bologna; Tiziana Balbi, Institute of Surgical Pathology, S. Orsola-Malpighi Hospital.

\section{Funding}

No funding received for this work.

\section{Availability of data and materials}

Not applicable.

\section{Authors' contributions}

DM: was involved in the design, implementation and writing of the article. FB: provided advice and input on each section of the manuscript and supervised the work of DM. EKS provided advice and input on each section of the manuscript and supervised the work of DM. MP: senior and corresponding author, was involved in the design, implementation and writing of the article and supervised the work of DM. All authors read and approved the final manuscript.

\section{Competing interests}

The authors declares that they have no competing interests.

\section{Consent for publication}

Not applicable.

Ethics approval and consent to participate

Not applicable.

\section{Author details}

${ }^{1}$ Cesare Maltoni Cancer Research Center, Ramazzini Institute, 40010 Bentivoglio, Bologna, Italy. ${ }^{2}$ Department of Environmental Health Sciences, Johns Hopkins Bloomberg School of Public Health, 21205 Baltimore, MD, USA. ${ }^{3}$ Department of Environmental and Occupational Health, Milken Institute School of Public Health, The George Washington University, 950 New Hampshire Ave. NW, 4th Floor, Washington, DC 20052, USA.

Received: 21 May 2016 Accepted: 28 September 2016

Published online: 12 October 2016

\section{References}

1. Council NR. Human Biomonitoring for Environmental Chemicals. Washington: The National Academies Press; 2006.

2. Peakall DB, Walker $\mathrm{CH}$. The role of biomarkers in environmental assessment (3). Vertebrates. Ecotoxicology. 1994;3(3):173-9. doi:10.1007/BF00117082.

3. Atkinson AJ, Colburn WA, DeGruttola VG, DeMets DL, Downing GJ, Hoth DF, et al. Biomarkers and surrogate endpoints: Preferred definitions and conceptual framework*. Clin Pharmacol Ther. 2001;69(3):89-95.

4. Ioannidis JP, Panagiotou OA. Comparison of effect sizes associated with biomarkers reported in highly cited individual articles and in subsequent meta-analyses. JAMA. 2011;305(21):2200-10.

5. Healy GN, Matthews CE, Dunstan DW, Winkler EAH, Owen N. Sedentary time and cardio-metabolic biomarkers in US adults: NHANES 2003-06, vol. 5. 2011.

6. Van der Sluijs JP, Simon-Delso N, Goulson D, Maxim L, Bonmatin J-M, Belzunces LP. Neonicotinoids, bee disorders and the sustainability of pollinator services. Curr Opin Environ Sustain. 2013;5(3):293-305.

7. Chokshi DA, Farley TA. The Cost-Effectiveness of Environmental Approaches to Disease Prevention. N Engl J Med. 2012;367(4):295-7. doi:10.1056/ NEJMp1206268

8. Yamamoto KN, Hirota K, Kono K, Takeda S, Sakamuru S, Xia M, et al. Characterization of environmental chemicals with potential for DNA damage using isogenic DNA repair-deficient chicken DT40 cell lines. Environ Mol Mutagen. 2011:52(7):547-61. doi:10.1002/em.20656.

9. Albertini RJ, Anderson D, Douglas GR, Hagmar L, Hemminki K, Merlo F, et al. IPCS guidelines for the monitoring of genotoxic effects of carcinogens in humans. International Programme on Chemical Safety. Mutat Res. 2000; 463(2):111-72.

10. Norppa H. Cytogenetic biomarkers. IARC Sci Publ. 2004;157:179-205

11. Gordon DJ, Resio B, Pellman D. Causes and consequences of aneuploidy in cancer. Nat Rev Genet. 2012;13(3):189-203. doi:10.1038/nrg3123.

12. Torres EM, Williams BR, Amon A. Aneuploidy: cells losing their balance. Genetics. 2008;179(2):737-46. doi:10.1534/genetics.108.090878.

13. Dyer A, Jong K, Ratter J. Aneuploidy: a redefinition. Notes from the Royal Botanic Garden Edinburgh. 1970;30(1):177-82.

14. Hansemann D. Ueber asymmetrische Zelltheilung in Epithelkrebsen und deren biologische Bedeutung. Virchows Arch. 1890;119(2):299-326.

15. Wright MR. Marcella O'Grady Boveri (1863-1950): her three careers in biology. Isis. 1997:88(4):627-52

16. Satzinger $\mathrm{H}$. Theodor and Marcella Boveri: chromosomes and cytoplasm in heredity and development. Nat Rev Genet. 2008;9(3):231-8. doi:10.1038/ nrg2311.

17. Boveri T. Zur frage der entstehung maligner tumoren. Jena, Germany: Gustav Fischer; 1914

18. Boveri T. Über mehrpolige mitosen als mittel zur analyse des zellkerns. Verhandlungen der physicalischmedizinischen Gesselschaft zu Würzburg, Neu Folge. 1902;35:67-90.

19. Boveri T. Ergebnisse über die Konstitution der chromatischen Substanz des Zellkerns. Jena, Germany: Gustav Fischer; 1904.

20. Boveri T, Boveri M. The origin of malignant tumors. Baltimore, Maryland, USA: Williams and Wilkins Company; 1929. 
21. Boveri T. Concerning the Origin of Malignant Tumours by Theodor Boveri. Translated and annotated by Henry Harris. J Cell Sci. 2008;121(Supplement 1) 1-84. doi:10.1242/jcs.025742.

22. McClintock B. A cytological and genetical study of triploid maize. Genetics. 1929;14(2):180

23. Huxley J. Cancer biology: comparative and genetic*. Biol Rev. 1956;31(4): 474-513. doi:10.1111/j.1469-185X.1956.tb01558.x.

24. Lejeune J, Gautier M, Turpin R. Study of somatic chromosomes from 9 mongoloid children. C R Hebd Seances Acad Sci. 1959;248(11):1721-2.

25. Hauschka TS. The chromosomes in ontogeny and oncogeny. Cancer Res. 1961;21:957-74

26. Baranov VS, Dyban AP. Embryonic development and characteristics of karyotype of mouse embryos with centric fusion of chromosomes (Robertsonian translocation). Sov J Dev Biol. 1971;2(2):132-40.

27. Oshimura M, Barrett JC. Chemically induced aneuploidy in mammalian cells: Mechanisms and biological significance in cancer. Environ Mutagen. 1986; 8(1):129-59. doi:10.1002/em.2860080112.

28. Lyle R, Béna F, Gagos S, Gehrig C, Lopez G, Schinzel A, et al. Genotypephenotype correlations in Down syndrome identified by array CGH in 30 cases of partial trisomy and partial monosomy chromosome 21. Eur J Hum Genet. 2009;17(4):454-66. doi:10.1038/ejhg.2008.214.

29. Papoulidis I, Papageorgiou E, Siomou E, Oikonomidou E, Thomaidis L, Vetro A, et al. A patient with partial trisomy 21 and $7 q$ deletion expresses mild Down syndrome phenotype. Gene. 2014;536(2):441-3. doi:10.1016/j.gene. 2013.11.078.

30. Korbel JO, Tirosh-Wagner T, Urban AE, Chen XN, Kasowski M, Dai L, et al. The genetic architecture of Down syndrome phenotypes revealed by high-resolution analysis of human segmental trisomies. Proc Natl Acad Sci U S A. 2009;106(29):12031-6. doi:10.1073/pnas.0813248106.

31. Redheendran R, Neu RL, Bannerman RM. Long survival in trisomy-13syndrome: 21 cases including prolonged survival in two patients 11 and 19 years old. Am J Med Genet. 1981;8(2):167-72. doi:10.1002/ajmg.1320080207.

32. Petek E, Pertl B, Tschernigg M, Bauer M, Mayr J, Wagner $K$, et al. Characterisation of a 19-year-old "long-term survivor" with Edwards syndrome. Genet Couns. 2003;14(2):239-44.

33. Pavelka N, Rancati G, Zhu J, Bradford WD, Saraf A, Florens L, et al. Aneuploidy confers quantitative proteome changes and phenotypic variation in budding yeast. Nature. 2010:468(7321):321-5. doi:10.1038/nature09529.

34. Duncan AW, Hanlon Newell AE, Bi W, Finegold MJ, Olson SB, Beaudet AL, et al. Aneuploidy as a mechanism for stress-induced liver adaptation. J Clin Invest. 2012;122(9):3307-15. doi:10.1172/jci64026.

35. Muotri AR, Gage FH. Generation of neuronal variability and complexity. Nature. 2006:441(7097):1087-93. doi:10.1038/nature04959.

36. Knouse KA, Wu J, Whittaker CA, Amon A. Single cell sequencing reveals low levels of aneuploidy across mammalian tissues. Proc Natl Acad Sci U S A. 2014;111(37):13409-14. doi:10.1073/pnas.1415287111.

37. lourov IY, Vorsanova SG, Liehr T, Yurov YB. Aneuploidy in the normal, Alzheimer's disease and ataxia-telangiectasia brain: differential expression and pathological meaning. Neurobiol Dis. 2009;34(2):212-20. doi:10.1016/j. nbd.2009.01.003.

38. El-Sayed SS, El-Sadany M, Tabll AA, Soltan A, El-Dosoky I, Attallah AM. DNA ploidy and liver cell dysplasia in liver biopsies from patients with liver cirrhosis. Can J Gastroenterol. 2004;18(2):87-91.

39. Quick EL, Parry EM, Parry JM. Do oestrogens induce chromosome specific aneuploidy in vitro, similar to the pattern of aneuploidy seen in breast cancer? Mutat Res. 2008;651(1-2):46-55. doi:10.1016/j.mrgentox. 2007.10.021.

40. Storchova Z. The causes and consequences of aneuploidy in eukaryotic cells. Aneuploidy in health and disease Rijecka (Croatia): InTech Europe. 2012. p. 1-21.

41. Duesberg P, Rasnick D, Li R, Winters L, Rausch C, Hehlmann R. How aneuploidy may cause cancer and genetic instability. Anticancer Res. 1999; 19(6a):4887-906

42. Tsutsui T, Maizumi H, McLachlan JA, Barrett JC. Aneuploidy induction and cell transformation by diethylstilbestrol: a possible chromosomal mechanism in carcinogenesis. Cancer Res. 1983;43(8):3814-21.

43. Tiwari D, Kamble J, Chilgunde S, Patil P, Maru G, Kawle D, et al. Clastogenic and mutagenic effects of bisphenol A: an endocrine disruptor. Mutat Res. 2012;743(1-2):83-90. doi:10.1016/j.mrgentox.2011.12.023.

44. Ried T, Hu Y, Difilippantonio MJ, Ghadimi BM, Grade M, Camps J. The consequences of chromosomal aneuploidy on the transcriptome of cancer cells. Biochim Biophys Acta. 2012;1819(7):784-93. doi:10.1016/j. bbagrm.2012.02.020

45. Gemoll T, Habermann JK, Becker S, Szymczak S, Upender MB, Bruch HP, et al. Chromosomal aneuploidy affects the global proteome equilibrium of colorectal cancer cells. Anal Cell Pathol (Amst). 2013;36(5-6):149-61. doi:10.3233/acp-140088.

46. Pavelka N, Rancati G. Never in neutral: a systems biology and evolutionary perspective on how aneuploidy contributes to human diseases. Cytogenet Genome Res. 2013;139(3):193-205. doi:10.1159/000348303.

47. Nicholson JM, Cimini D. How mitotic errors contribute to karyotypic diversity in cancer. Adv Cancer Res. 2011;112:43-75. doi:10.1016/b978-012-387688-1.00003-x.

48. Duesberg P, Rausch C, Rasnick D, Hehlmann R. Genetic instability of cancer cells is proportional to their degree of aneuploidy. Proc Natl Acad Sci U S A. 1998:95(23):13692-7.

49. Duesberg P, Mandrioli D, McCormack A, Nicholson JM. Is carcinogenesis a form of speciation? Cell Cycle. 2011;10(13):2100-14.

50. Schulze S, Petersen I. Gender and ploidy in cancer survival. Cell Oncol (Dordr). 2011;34(3):199-208. doi:10.1007/s13402-011-0013-0.

51. Nicholson JM, Cimini D. Cancer karyotypes: survival of the fittest. Front Oncol. 2013;3:148. doi:10.3389/fonc.2013.00148.

52. Ozery-Flato M, Linhart C, Trakhtenbrot L, Izraeli S, Shamir R. Large-scale analysis of chromosomal aberrations in cancer karyotypes reveals two distinct paths to aneuploidy. Genome Biol. 2011;12(6):R61. doi:10.1186/gb2011-12-6-r61.

53. Brown JD, O'Neill RJ. Chromosomes, Conflict, and Epigenetics: Chromosomal Speciation Revisited. Annu Rev Genomics Hum Genet. 2010; 11(1):291-316. doi:10.1146/annurev-genom-082509-141554.

54. Van Valen LM, Maiorana VC. HeLa, a new microbial species. Evolutionary Theory. 1991;10:71-4.

55. Nowell PC. The clonal evolution of tumor cell populations. Science. 1976; 194(4260):23-8.

56. Duesberg P, lacobuzio-Donahue C, Brosnan JA, McCormack A, Mandrioli D Chen L. Origin of metastases: subspecies of cancers generated by intrinsic karyotypic variations. Cell Cycle. 2012;11(6):1151-66. doi:10.4161/cc.11.6.19580.

57. Rehg JE, Bush D, Ward JM. The utility of immunohistochemistry for the identification of hematopoietic and lymphoid cells in normal tissues and interpretation of proliferative and inflammatory lesions of mice and rats. Toxicol Pathol. 2012;40(2):345-74. doi:10.1177/0192623311430695.

58. Lippman SM, Hawk ET. Cancer prevention: from 1727 to milestones of the past 100 years. Cancer Res. 2009;69(13):5269-84.

59. Slaughter DP, Southwick HW, Smejkal W. Field cancerization in oral stratified squamous epithelium; clinical implications of multicentric origin. Cancer. 1953;6(5):963-8.

60. Bergström R, Sparén P, Adami HO. Trends in cancer of the cervix uteri in Sweden following cytological screening. Br J Cancer. 1999;81(1):159-66. doi:10.1038/sj.bjc.6690666.

61. Zauber AG, Winawer SJ, O'Brien MJ, Lansdorp-Vogelaar I, van Ballegooijen M, Hankey BF, et al. Colonoscopic Polypectomy and Long-Term Prevention of Colorectal-Cancer Deaths. N Engl J Med. 2012;366(8):687-96. doi:10.1056/ NEJMoa1100370.

62. Hvid-Jensen F, Pedersen L, Drewes AM, Sørensen HT, Funch-Jensen P. Incidence of Adenocarcinoma among Patients with Barrett's Esophagus. N Engl J Med. 2011;365(15):1375-83. doi:10.1056/NEJMoa1103042.

63. Lippman SM, Sudbø J, Hong WK. Oral Cancer Prevention and the Evolution of Molecular-Targeted Drug Development. J Clin Oncol. 2005;23(2):346-56. doi:10.1200/jco.2005.09.128.

64. Reddy KK, Farber MJ, Bhawan J, Geronemus RG, Rogers GS. Atypical (dysplastic) nevi: outcomes of surgical excision and association with melanoma. JAMA Dermatol. 2013;149(8):928-34. doi:10.1001/jamadermatol.2013.4440.

65. Elzagheid A, Kuopio T, Collan Y. Implementation of DNA cytometric measurements in fine-needle aspiration biopsy diagnostics of breast disease. Cancer. 2004;102(6):380-8. doi:10.1002/cncr.20641.

66. Steinbeck RG. Proliferation and DNA aneuploidy in mild dysplasia imply early steps of cervical carcinogenesis. Acta Oncol (Stockh). 1997;36(1):3-12.

67. Li G, Guillaud M, LeRiche J, McWilliams A, Gazdar A, Lam S, et al. Automated sputum cytometry for detection of intraepithelial neoplasias in the lung. Anal Cell Pathol (Amst). 2012:35(3):187-201. doi:10.3233/acp-2012-0053.

68. Massion PP, Zou Y, Uner H, Kiatsimkul P, Wolf HJ, Baron AE, et al. Recurrent genomic gains in preinvasive lesions as a biomarker of risk for lung cancer. PLoS One. 2009;4(6):e5611. doi:10.1371/journal.pone.0005611. 
69. Baretton G, Vogt T, Valina C, Schneiderbanger K, Lohrs U. Prostate cancers and potential precancerous conditions: DNA cytometric investigations and interphase cytogenetics. Verh Dtsch Ges Pathol. 1993;77:86-92.

70. North JP, Garrido MC, Kolaitis NA, LeBoit PE, McCalmont TH, Bastian BC. Fluorescence in situ hybridization as an ancillary tool in the diagnosis of ambiguous melanocytic neoplasms: a review of 804 cases. Am J Surg Pathol. 2014;38(6):824-31. doi:10.1097/pas.0000000000000189.

71. Giaretti W, Monteghirfo S, Pentenero M, Gandolfo S, Malacarne D, Castagnola P. Chromosomal instability, DNA index, dysplasia, and subsite in oral premalignancy as intermediate endpoints of risk of cancer. Cancer Epidemiol Biomarkers Prev. 2013;22(6):1133-41. doi:10.1158/1055-9965.epi13-0147.

72. Menke-Pluymers MB, Mulder AH, Hop WC, van Blankenstein M, Tilanus HW. Dysplasia and aneuploidy as markers of malignant degeneration in Barrett's oesophagus. The Rotterdam Oesophageal Tumour Study Group. Gut. 1994 35(10):1348-51.

73. Singh M, Mehrotra S, Kalra N, Singh U, Shukla Y. Correlation of DNA ploidy with progression of cervical cancer. J Cancer Epidemiol. 2008;2008:298495. doi:10.1155/2008/298495

74. Haase D, Germing U, Schanz J, Pfeilstocker M, Nosslinger T, Hildebrandt B, et al. New insights into the prognostic impact of the karyotype in MDS and correlation with subtypes: evidence from a core dataset of 2124 patients. Blood. 2007:110(13):4385-95. doi:10.1182/blood-2007-03-082404.

75. Giwercman A, Clausen OP, Skakkebaek NE. Carcinoma in situ of the testis: aneuploid cells in semen. Br Med J (Clin Res Ed). 1988;296(6639):1762-4.

76. Senovilla L, Galluzzi L, Castedo M, Kroemer G. Immunological control of cell cycle aberrations for the avoidance of oncogenesis: the case of tetraploidy. Ann N Y Acad Sci. 2013;1284:57-61. doi:10.1111/nyas.12072.

77. Nicholson JM, Cimini D. Doubling the deck: Tetraploidy induces chromosome shuffling and cancer. Cell Cycle. 2012;11(18):3354-5. doi:10.4161/cc.21850.

78. Lv L, Zhang T, Yi Q, Huang Y, Wang Z, Hou H, et al. Tetraploid cells from cytokinesis failure induce aneuploidy and spontaneous transformation of mouse ovarian surface epithelial cells. Cell Cycle. 2012;11(15):2864-75. doi:10.4161/cc.21196.

79. Naber SP. Molecular Pathology - Detection of Neoplasia. N Engl J Med. 1994;331(22):1508-10. doi:10.1056/NEJM199412013312208.

80. Greaves M, Maley CC. Clonal evolution in cancer. Nature. 2012:481(7381): 306-13. doi:10.1038/nature10762.

81. Van Hummelen P, Deleener A, Vanparys P, Kirsch-Volders M. Discrimination of aneuploidogens from clastogens by C-banding, DNA and area measurements of micronuclei from mouse bone marrow. Mutat Res. 1992; 271(1):13-28. doi:http://dx.doi.org/10.1016/0165-1161(92)90028-K.

82. Rosefort C, Fauth E, Zankl H. Micronuclei induced by aneugens and clastogens in mononucleate and binucleate cells using the cytokinesis block assay. Mutagenesis. 2004;19(4):277-84. doi:10.1093/mutage/geh028.

83. Yamamoto M, Wakata A, Aoki Y, Miyamae Y, Kodama S. Induction of a whole chromosome loss by colcemid in human cells elucidated by discrimination between FISH signal overlap and chromosome loss. Mutat Res. 2013;749(1-2):39-48. doi:10.1016/j.mrfmmm.2013.06.001.

84. Sasaki YF, Sekihashi K, Izumiyama F, Nishidate E, Saga A, Ishida K, et al. The comet assay with multiple mouse organs: comparison of comet assay results and carcinogenicity with 208 chemicals selected from the IARC monographs and U.S. NTP Carcinogenicity Database. Crit Rev Toxicol. 2000; 30(6):629-799. doi:10.1080/10408440008951123.

85. Recio L, Hobbs C, Caspary W, Witt KL. Dose-response Assessment of Four Genotoxic Chemicals in a Combined Mouse and Rat Micronucleus and Comet Assay Protocol. J Toxicol Sci. 2010;35(2):149-62.

86. Eastmond DA, Tucker JD. Identification of aneuploidy-inducing agents using cytokinesis-blocked human lymphocytes and an antikinetochore antibody. Environ Mol Mutagen. 1989;13(1):34-43. doi:10.1002/em.2850130104.

87. Tsutsui T, Hayashi N, Maizumi H, Huff J, Barrett JC. Benzene-, catechol-, hydroquinone- and phenol-induced cell transformation, gene mutations, chromosome aberrations, aneuploidy, sister chromatid exchanges and unscheduled DNA synthesis in Syrian hamster embryo cells. Mutat Res. 1997;373(1):113-23. doi:http://dx.doi.org/10.1016/ S0027-5107(96)00196-0.

88. Gowans ID, Lorimore SA, Mcllrath JM, Wright EG. Genotype-dependent induction of transmissible chromosomal instability by gamma-radiation and the benzene metabolite hydroquinone. Cancer Res. 2005;65(9):3527-30. doi:10.1158/0008-5472.can-04-4242
89. Morgan WF. Non-targeted and delayed effects of exposure to ionizing radiation: II. Radiation-induced genomic instability and bystander effects in vivo, clastogenic factors and transgenerational effects. Radiat Res. 2003; 159(5):581-96.

90. Lebedev IN, Ostroverkhova NV, Nikitina TV, Sukhanova NN, Nazarenko SA. Features of chromosomal abnormalities in spontaneous abortion cell culture failures detected by interphase FISH analysis. Eur J Hum Genet. 2004; 12(7):513-20. doi:10.1038/sj.ejhg.5201178.

91. Olson SB, Magenis RE. Preferential paternal origin of de novo structural chromosome rearrangements. The cytogenetics of mammalian autosomal rearrangements Liss, New York. 1988. p. 583-99.

92. Chandley AC. On the parental origin of de novo mutation in man. J Med Genet. 1991:28(4):217-23.

93. Crow JF. The origins, patterns and implications of human spontaneous mutation. Nat Rev Genet. 2000;1(1):40-7. doi:10.1038/35049558.

94. Hassold T, Hunt P. To err (meiotically) is human: the genesis of human aneuploidy. Nat Rev Genet. 2001;2(4):280-91. doi:10.1038/35066065.

95. Shi Q, Martin RH. Aneuploidy in human spermatozoa: FISH analysis in men with constitutional chromosomal abnormalities, and in infertile men. Reproduction. 2001;121(5):655-66. doi:10.1530/rep.0.1210655.

96. Tempest HG, Griffin DK. The relationship between male infertility and increased levels of sperm disomy. Cytogenet Genome Res. 2004;107(1-2): 83-94. doi:10.1159/000079575.

97. Templado C, Uroz L, Estop A. New insights on the origin and relevance of aneuploidy in human spermatozoa. Mol Hum Reprod. 2013;19(10):634-43. doi:10.1093/molehr/gat039.

98. Martin $\mathrm{RH}, \mathrm{Ko}$, Rademaker A. Distribution of aneuploidy in human gametes: comparison between human sperm and oocytes. Am J Med Genet. 1991;39(3):321-31. doi:10.1002/ajmg.1320390315.

99. Martin RH. Meiotic chromosome abnormalities in human spermatogenesis. Reprod Toxicol. 2006;22(2):142-7.

100. Boyd PA, Loane M, Garne E, Khoshnood B, Dolk H, Group E. Sex chromosome trisomies in Europe: prevalence, prenatal detection and outcome of pregnancy. Eur J Hum Genet. 2011;19(2):231-4. doi:10.1038/ ejhg.2010.148.

101. Morris JK, Alberman E, Scott C, Jacobs P. Is the prevalence of Klinefelter syndrome increasing? Eur J Hum Genet. 2008;16(2):163-70.

102. Rodrigo L, Peinado V, Mateu E, Remohi J, Pellicer A, Simon C, et al. Impact of different patterns of sperm chromosomal abnormalities on the chromosomal constitution of preimplantation embryos. Fertil Steril. 2010; 94(4):1380-6. doi:10.1016/j.fertnstert.2009.05.061.

103. Magli MC, Gianaroli L, Ferraretti AP, Gordts S, Fredericks V, Crippa A. Paternal contribution to aneuploidy in preimplantation embryos. Reprod Biomed Online. 2009;18(4):536-42.

104. Ghoraeian P, Mozdarani H, Aleyasin A, Alizadeh-Nili H. Frequency of sex chromosomal disomy in spermatozoa of normal and oligozoospermic Iranian patients and its effects on fertilisation and implantation rates after ICSI. Andrologia. 2013;45(1):46-55. doi:10.1111/j.1439-0272.2012.01309.x.

105. Rubio C, Gil-Salom M, Simon C, Vidal F, Rodrigo L, Minguez Y, et al. Incidence of sperm chromosomal abnormalities in a risk population: relationship with sperm quality and ICSI outcome. Hum Reprod. 2001;16(10):2084-92.

106. McAuliffe ME, Williams PL, Korrick SA, Dadd R, Perry MJ. The association between sperm sex chromosome disomy and semen concentration, motility and morphology. Hum Reprod. 2012;27(10):2918-26. doi:10.1093/ humrep/des302.

107. Sun F, Mikhaail-Philips M, Sun F, et al. Reduced meiotic recombination on the $X Y$ bivalent is correlated with an increased incidence of sex chromosome aneuploidy in men with non-obstructive azoospermia. Mol Hum Reprod. 2008;14(7):399-404. doi:10.1093/molehr/gan030.

108. Ferguson KA, Wong EC, Chow V, Nigro M, Ma S. Abnormal meiotic recombination in infertile men and its association with sperm aneuploidy. Hum Mol Genet. 2007;16(23):2870-9. doi:10.1093/hmg/ddm246.

109. Pacchierotti F, Eichenlaub-Ritter U. Environmental Hazard in the Aetiology of Somatic and Germ Cell Aneuploidy. Cytogenet Genome Res. 2011; 133(2-4):254-68. doi:10.1159/000323284.

110. Marchetti F, Bishop J, Gingerich J, Wyrobek AJ. Meiotic interstrand DNA damage escapes paternal repair and causes chromosomal aberrations in the zygote by maternal misrepair. Sci Rep. 2015;5:7689. doi:10.1038/srep07689.

111. Oppedisano L, Haines G, Hrabchak C, Fimia G, Elliott R, Sassone-Corsi P, et al. The rate of aneuploidy is altered in spermatids from infertile mice. Hum Reprod. 2002;17(3):710-7. doi:10.1093/humrep/17.3.710. 
112. Schiffer C, Müller A, Egeberg DL, Alvarez L, Brenker C, Rehfeld A, et al. Direct action of endocrine disrupting chemicals on human sperm. EMBO Rep. 2014;15(7):758-65. doi:10.15252/embr.201438869.

113. Martin RH, Hildebrand K, Yamamoto J, Rademaker A, Barnes M, Douglas G, et al. An increased frequency of human sperm chromosomal abnormalities after radiotherapy. Mutat Res. 1986;174(3):219-25.

114. Martin RH, Rademaker A, Hildebrand K, Barnes M, Arthur K, Ringrose T, et al. A comparison of chromosomal aberrations induced by in vivo radiotherapy in human sperm and lymphocytes. Mutat Res. 1989;226(1):21-30.

115. Robbins WA. Cytogenetic damage measured in human sperm following cancer chemotherapy. Mutat Res. 1996;355(1-2):235-52.

116. Schrader SM, Marlow KL. Assessing the reproductive health of men with occupational exposures. Asian J Androl. 2014;16(1):23-30. doi:10.4103/1008$682 \times .122352$.

117. Huang LP, Lee CC, Hsu PC, Shih TS. The association between semen quality in workers and the concentration of di(2-ethylhexyl) phthalate in polyvinyl chloride pellet plant air. Fertil Steril. 2011;96(1):90-4. doi:10.1016/j.fertnstert. 2011.04.093

118. Migliore L, Naccarati A, Zanello A, Scarpato R, Bramanti L, Mariani M Assessment of sperm DNA integrity in workers exposed to styrene. Hum Reprod. 2002;17(11):2912-8.

119. Sanchez-Pena LC, Reyes BE, Lopez-Carrillo L, Recio R, Moran-Martinez J, Cebrian ME, et al. Organophosphorous pesticide exposure alters sperm chromatin structure in Mexican agricultural workers. Toxicol Appl Pharmacol. 2004;196(1):108-13. doi:10.1016/j.taap.2003.11.023.

120. Xia Y, Cheng S, Bian Q, Xu L, Collins MD, Chang HC, et al. Genotoxic effects on spermatozoa of carbaryl-exposed workers. Toxicol Sci. 2005;85(1):615-23. doi:10.1093/toxsci/kfi066.

121. Bian Q, Xu LC, Wang SL, Xia YK, Tan LF, Chen JF, et al. Study on the relation between occupational fenvalerate exposure and spermatozoa DNA damage of pesticide factory workers. Occup Environ Med. 2004;61(12):999-1005. doi:10.1136/oem.2004.014597.

122. Naha N, Chowdhury AR. Inorganic lead exposure in battery and paint factory: effect on human sperm structure and functional activity. J UOEH. 2006;28(2):157-71.

123. Hsu PC, Chang HY, Guo YL, Liu YC, Shih TS. Effect of smoking on blood lead levels in workers and role of reactive oxygen species in lead-induced sperm chromatin DNA damage. Fertil Steril. 2009;91(4):1096-103. doi:10.1016/j. fertnstert.2008.01.005.

124. Marchetti F, Eskenazi B, Weldon RH, Li G, Zhang L, Rappaport SM, et al. Occupational exposure to benzene and chromosomal structural aberrations in the sperm of Chinese men. Environ Health Perspect. 2012;120(2):229-34. doi:10.1289/ehp.1103921.

125. NTP. Report on Carcinogens. 12th ed. Collingdale, Pennsylvania, USA: DIANE Publishing Company; 2011.

126. Ji Z, Weldon RH, Marchetti F, Chen H, Li G, Xing C, et al. Comparison of aneuploidies of chromosomes 21, $X$, and $Y$ in the blood lymphocytes and sperm of workers exposed to benzene. Environ Mol Mutagen. 2012;53(3): 218-26. doi:10.1002/em.21683.

127. Milosevic-Djordjevic O, Stosic I, Grujicic D, Zelen I, Sazdanovic P. Chromosomal instability in peripheral blood lymphocytes of patients with reproductive failure assessed by micronucleus assay. Arh Hig Rada Toksikol. 2012;63(3):367-75. doi:10.2478/10004-1254-63-2012-2225.

128. Migliore L, Colognato R, Naccarati A, Bergamaschi E. Relationship between genotoxicity biomarkers in somatic and germ cells: findings from a biomonitoring study. Mutagenesis. 2006;21(2):149-52. doi:10.1093/mutage/gel012.

129. Peterson RA, Krull DL, Butler L. Applications of Laser Scanning Cytometry in Immunohistochemistry and Routine Histopathology. Toxicol Pathol. 2008; 36(1):117-32. doi:10.1177/0192623307312704.

130. Al-Kofahi Y, Lassoued W, Grama K, Nath SK, Zhu J, Oueslati R, et al. Cellbased quantification of molecular biomarkers in histopathology specimens. Histopathology. 2011;59(1):40-54. doi:10.1111/j.1365-2559.2011.03878.x.

131. Pozarowski P, Holden E, Darzynkiewicz Z. Laser Scanning Cytometry: Principles and Applications_-An Update. In: Taatjes DJ, Roth J, editors. Cell Imaging Techniques. Methods in Molecular Biology. New York City: Humana Press; 2013. p. 187-212.

132. Perry MJ, Chen X, Lu X. Automated scoring of multiprobe FISH in human spermatozoa. Cytometry A. 2007:71(11):968-72. doi:10.1002/cyto.a.20468.

133. Perry MJ, Chen X, McAuliffe ME, Maity A, Deloid GM. Semi-automated scoring of triple-probe FISH in human sperm: methods and further validation. Cytometry A. 2011;79(8):661-6. doi:10.1002/cyto.a.21078.
134. Martinez G, Gillois P, Le Mitouard M, Borye R, Esquerre-Lamare C, Satre V, et al. FISH and tips: a large scale analysis of automated versus manual scoring for sperm aneuploidy detection. Basic Clin Androl. 2013;23:13. doi:10.1186/2051-4190-23-13.

135. Bishop R. Applications of fluorescence in situ hybridization (FISH) in detecting genetic aberrations of medical significance. Biosci Horiz. 2010;3(1): 85-95. doi:10.1093/biohorizons/hzq009.

136. Vorsanova SG, Yurov YB, lourov IY. Human interphase chromosomes: a review of available molecular cytogenetic technologies. Mol Cytogenet. 2010;3:1. doi:10.1186/1755-8166-3-1.

137. Yurov YB, Vorsanova SG, lourov IY. Human Interphase Chromosomes: Biomedical Aspects. Berlin: Springer; 2013.

138. Byers RJ, Hitchman ER. Quantum Dots Brighten Biological Imaging. Prog Histochem Cytochem. 2011;45(4):201-37. doi:http://dx.doi.org/10.1016/j. proghi.2010.11.001.

139. Bentolila LA. Direct in situ hybridization with oligonucleotide functionalized quantum dot probes. Methods Mol Biol. 2010;659:147-63. doi:10.1007/9781-60761-789-1_10.

140. Yusuf M, Bauer DL, Lipinski DM, MacLaren RE, Wade-Martins R, Mir KU, et al. Combining M-FISH and Quantum Dot technology for fast chromosomal assignment of transgenic insertions. BMC Biotechnol. 2011;11:121. doi:10.1186/1472-6750-11-121.

141. Zanini C, Gerbaudo E, Ercole E, Vendramin A, Forni M. Evaluation of two commercial and three home-made fixatives for the substitution of formalin: a formaldehyde-free laboratory is possible. Environ Health. 2012;11:59. doi:10.1186/1476-069x-11-59.

142. Dejmek A, Zendehrokh N, Tomaszewska M, Edsjö A. Preparation of DNA from cytological material. Cancer Cytopathol. 2013;121(7):344-53. doi:10.1002/cncy.21276.

143. Milcheva R, Janega P, Celec P, Russev R, Babal P. Alcohol based fixatives provide excellent tissue morphology, protein immunoreactivity and RNA integrity in paraffin embedded tissue specimens. Acta Histochem. 2013: 115(3):279-89. doi:10.1016/j.acthis.2012.08.002

144. Ahram M, Flaig MJ, Gillespie JW, Duray PH, Linehan WM, Ornstein DK, et al. Evaluation of ethanol-fixed, paraffin-embedded tissues for proteomic applications. Proteomics. 2003:3(4):413-21. doi:10.1002/pmic. 200390056

145. Gillespie JW, Best CJ, Bichsel VE, Cole KA, Greenhut SF, Hewitt SM, et al. Evaluation of non-formalin tissue fixation for molecular profiling studies. Am J Pathol. 2002;160(2):449-57. doi:10.1016/s0002-9440(10)64864-x.

146. Balbi T, Cicognani A, Esposti PD, Pierini G. Microwave processing and ethanol-based fixation in forensic pathology: an addendum of further scanning electron microscope observations. Am J Forensic Med Pathol. 2009;30(3):242-5. doi:10.1097/PAF.0b013e31819d222e.

147. Kniggendorf AK, Gaul TW, Meinhardt-Wollweber M. Effects of ethanol, formaldehyde, and gentle heat fixation in confocal resonance Raman microscopy of purple nonsulfur bacteria. Microsc Res Tech. 2011;74(2): 177-83. doi:10.1002/jemt.20889.

148. Derradji H, Bekaert S, VAN Oostveldt P, Baatout S. Comparison of Different Protocols for Telomere Length Estimation by Combination of Quantitative Fluorescence In Situ Hybridization (Q-FISH) and Flow Cytometry in Human Cancer Cell Lines. Anticancer Res. 2005;25(2A):1039-50.

149. Panzacchi S, Boiani S, Mandrioli D, Piccioli M, Belpoggi F. Applying immunohistochemistry to alcohol-fixed paraffinembedded tissues: An innovative technique to reduce use of formaldehyde. Eur J Oncol. 2013; 18(2):75-83.

150. NRC. Review of EPA's Integrated Risk Information System (IRIS) Process. Washington: The National Academies Press; 2014.

151. Terret ME, Chaigne A, Verlhac MH. Mouse oocyte, a paradigm of cancer cell. Cell Cycle. 2013;12(21):3370-6. doi:10.4161/cc.26583.

152. Marchetti F, Massarotti A, Yauk CL, Pacchierotti F, Russo A. The adverse outcome pathway (AOP) for chemical binding to tubulin in oocytes leading to aneuploid offspring. Environ Mol Mutagen. 2015. doi:10.1002/ em.21986.

153. Garcia-Ferreyra J, Luna D, Villegas L, Romero R, Zavala P, Hilario R, et al. High Aneuploidy Rates Observed in Embryos Derived from Donated Oocytes are Related to Male Aging and High Percentages of Sperm DNA Fragmentation. Clin Med Insights Reprod Health. 2015:9:21-7. doi:10.4137/cmrh.s32769.

154. Perry M. Chemically induced DNA damage and sperm and oocyte repair machinery: the story gets more interesting. Asian J Androl. 2015. doi:10. 4103/1008-682x.156118. 
155. Sills ES, Anderson RE, McCaffrey M, Li X, Arrach N, Wood SH. Gestational surrogacy and the role of routine embryo screening: Current challenges and future directions for preimplantation genetic testing. Birth Defects Res C Embryo Today. 2015. doi:10.1002/bdrc.21112.

156. Fenech M, Kirsch-Volders M, Rossnerova A, Sram R, Romm H, Bolognesi C, et al. HUMN project initiative and review of validation, quality control and prospects for further development of automated micronucleus assays using image cytometry systems. Int J Hyg Environ Health. 2013;216(5):541-52. doi:10.1016/j.jijheh.2013.01.008.

157. Perry MJ, Young HA, Grandjean P, Halling J, Petersen MS, Martenies SE, et al. Sperm Aneuploidy in Faroese Men with Lifetime Exposure to

Dichlorodiphenyldichloroethylene ( $p, p$-DDE) and Polychlorinated Biphenyl (PCB) Pollutants. Environ Health Perspect. 2016;124(7):951-6. doi:10.1289/ ehp.1509779.

158. IARC. Polychlorinated biphenyls and polybrominated biphenyls. IARC monographs on the evaluation of carcinogenic risks to humans/World Health Organization, International Agency for Research on Cancer. 2016. p. 107.

Submit your next manuscript to BioMed Central and we will help you at every step:

- We accept pre-submission inquiries

- Our selector tool helps you to find the most relevant journal

- We provide round the clock customer support

- Convenient online submission

- Thorough peer review

- Inclusion in PubMed and all major indexing services

- Maximum visibility for your research

Submit your manuscript at www.biomedcentral.com/submit
Biomed Central 